\title{
La pseudocomprensión. Un acuerdo entre los medios y sus clientes
}

\author{
Recibido: 01 de noviembre de 2016 \\ Aceptado: 12 de junio de 2017 \\ Publicado: 27 de noviembre de 2017
}

\author{
Claudia Maya Franco \\ cmaya@udem.edu.co \\ Universidad de Medellín (Colombia)
}

Resumen: Entre los medios de comunicación y sus clientes se establece una relación que no se explica apelando a la ley de las causas y los efectos. Podría decirse más bien que se trata de una relación dialógica, profundamente arraigada en las lógicas propias de la oferta y la demanda. En este texto, a partir de la relación planteada por Heidegger (y que también es dialógica) entre comprensión y pseudo-comprensión, habla y habladurías (y haciendo referencia a la noción de industria cultural), se sugiere que el carácter muchas veces falaz del ejercicio de la información está determinado no solo por los medios y los intereses que detentan, sino por aquellos a quienes hemos denominado sus clientes.

Palabras clave: Medios de comunicación, comprensión, pseudo-comprensión, habla, rumores.

\begin{abstract}
A relationship is established between the media and its clients that is not explained by appealing to the law of causes and effects. It could be said rather that it is a dialogic relationship, deeply rooted in the logic of supply and demand. In this text, from the relationship proposed by Heidegger (and that is also dialogical) between understanding and pseudo-understanding, speech and gossip (and referring to the notion of cultural industry), it is suggested that the often fallacious character of the exercise of information is determined not only by the means and interests they hold, but by those to whom we have called their clients.
\end{abstract}

Key words: media, understanding, pseudo-understanding, talk, gossip. 


\section{Comprensión y pseudocomprensión}

Rasgos definitorios de la relación actual con los medios están contenidos en la siguiente afirmación de Heidegger: la "avidez de novedades" y el "querer saberlo todo," que cabría referir al afán por la primicia, por un lado, y a la necesidad de estar informado, al día, por el otro.

"Una muy ágil avidez de novedades y un inquieto querer saberlo todo, fingen una comprensión universal del "ser ahí". Pero en el fondo se sigue sin determinar ni preguntar qué es lo que se trata propiamente de comprender; se sigue sin comprender que el comprender mismo es un 'poder ser' que tiene que quedar en libertad únicamente en el 'ser ahí' más peculiar. En este aquietado compararse con todo, 'comprensivo' de todo, vuela el 'ser ahí' a un extrañamiento en que se le oculta el más peculiar 'poder ser'. El cadente 'ser en el mundo' es, en cuanto aquietador, tentador, al par, 'extrañador'” (Heidegger, 1995, 198).

Ambas actitudes configuran el ámbito de una pseudocomprensión en la que se cierran al intérprete el sentido de lo comprendido y (aún más) el del comprender mismo. Este ámbito común y homogeneizante (recorrido sin intermitencia por el espectro que ha horrorizado a los filósofos: el imperio de la opinión y la apariencia, tejido con el hilo de las "habladurías") es, sin embargo, el único suelo en el que puede librarse la lucha contra el "saber de oídas", el suelo en el que aún es posible la comprensión genuina y la posibilidad de la interpretación crítica.

Las "habladurías" (al decir de Heidegger) presuponen una apropiación aparente de la cotidianidad, una repetición acrítica que (en virtud de su presunta verdad) asume el estatuto de una autoridad que no es otra que la del consenso y, en ocasiones, la del falso consenso. Siendo la posibilidad de "comprenderlo" todo sin habérselo apropiado, crean una indiferente comprensión a la que nada se le oculta y de este modo cierran la comprensión. Es en este estado cerrado (por él y contra él) que se alcanza, según Heidegger, todo genuino comprender, interpretar y comunicar, volver a descubrir y apropiarse de nuevo.

Son la filosofía y la conciencia crítica, cuyo campo de acción está (en virtud de su pertenencia a la cultura) cada vez más profundamente preformado: las que están llamadas a lanzar preguntas que tiendan a conmover, a desestabilizar; este espacio de pseudocomprensión que, en la actualidad y en virtud del carácter prosumidor de los usuarios, se verifica de modo contundente, tanto en redes sociales como en medios de comunicación convencionales.

La pregunta y su orientación a la respuesta, acontecen en el lenguaje e implican una transformación del mismo, un paso, en términos de Heidegger, de la "habladuría" al "habla", en el que las palabras acuñadas recobren su significado e incluso sea necesario inventar nuevos modos de nombrar lo que es otro respecto de las "verdades" del consenso. Esta mutación e invención (producto de la injerencia del pensamiento sobre el lenguaje) dan cuenta de su carácter productivo, del mismo que le hace dejar atrás modos de nombrar ciertas palabras desposeídas de referente o usos caducos. 
Un primer paso consistiría, al menos, en formularse preguntas allí en donde reina la apariencia de la comprensión, asumir una actitud de sospecha que permita socavar el suelo de las certezas y conmover la tendencia acrítica a la aceptación. Se trata de una labor en el plano del lenguaje en el que acontecen, tanto las habladurías como el habla. En ambos casos se despliega la capacidad de comunicar un sentido mediante signos susceptibles de ser comprendidos, esto es, signos dirigidos a alguien. Las habladurías, pues, abren el camino al habla.

En la periferia de la pseudocomprensión florece (esporádicamente pero no por ello con poco ímpetu) la sospecha, la consiguiente pregunta y la posibilidad de pensamiento. Este pensamiento lo expresa un discurso elaborado con hilos tomados de la urdimbre complicada que tejen las habladurías y, por lo mismo, susceptible de ser no solo comprendido, sino, neutralizado, reaclimatado y normalizado en la mayoría de los casos.

El imperio de la opinión, al que Platón equiparaba con la ignorancia, es el suelo de la comprensión y del conocimiento. No conoce, en el sentido de no haber alcanzado la elaboración racional del concepto, quien tan solo tiene opiniones sobre el mismo. Así, cuando Sócrates pregunta a Teeteto por lo que son las ciencias (y este responde enumerando algunas de ellas) se pone en evidencia (a juicio de Sócrates) que ignora el concepto mismo de ciencia y tan solo provee información que no contribuye a la elaboración conceptual:

"Por consiguiente, cuando se pregunta lo que es la ciencia, es ponerse en ridículo el dar por respuesta el nombre de una ciencia, puesto que es responder sobre el objeto de la ciencia, y no sobre la ciencia misma, que es a la que se refiere la pregunta" (Platón, 1988: 196).

Se explica lo anterior porque el saber no radica en las impresiones sensibles, sino en el razonamiento que nos permite alcanzar el ser y la verdad" (Platón, 2013: 156). Guardando las proporciones, se produce un efecto similar, cuando ante la pregunta por la política se responde hablando sobre los políticos o sobre los partidos políticos. Se ha evadido, en ese caso, la elaboración racional del concepto de política.

La opinión, ese creer que se sabe que se vanagloria de sí mismo, constituye una primera entrada, un a priori indispensable en el acceso al conocimiento. El dialogo mismo da cuenta de cómo, a partir del intercambio dialéctico de las opiniones, va elaborándose un saber a propósito del objeto que les ocupa a Sócrates y Teeteto: la ciencia. En contra de la opinión, pero tomándola como presupuesto, se han realizado obras humanas como las matemáticas y la filosofía: mediaciones del conocimiento del mundo y de su comprensión. Las opiniones son parte irrenunciable de los individuos, constituyen la realidad histórica de su ser, su finitud.

El carácter abarcante de las mismas, sin embargo, las hace asumir la apariencia de la verdad, impidiendo la toma de distancia que permitiría refutarlas y ponerse en el camino del conocimiento. Todo avance en el conocimiento ha tenido como punto de partida un 
reconocimiento de que lo que se creía saber era tan sólo apariencia. Dicho reconocimiento abre el espacio en el que se puede responder a la exigencia que Nietzsche hace a los espíritus positivos, es decir, a la exigencia de poner "en lugar de lo inverosímil, algo más verosímil, y a veces, en lugar de un error, otro distinto" (Nietzsche, 1994: 21). Se trata de sustituir la opinión o el prejuicio tenidos por verdaderos, por algo más válido. No más verdadero, sino quizá tan solo más plausible, adecuado, conveniente, seguro. Esta sustitución implica la puesta en suspenso, la crítica, de la opinión.

Las principales fuentes sociales de prejuicios han sido: la autoridad, en la medida en que no permite un uso autónomo de la razón; la fe dogmática en la tradición, ante la que sólo resta callar, asumiéndola tal y como es y, finalmente, la posición de legitimación respecto de las verdades que circulan por consenso, legitimación que se traduce en una recepción absolutamente acrítica de las mismas y muchas veces en su reproducción. A partir de la explosión, e incontenible expansión de los medios de comunicación (a la que actualmente se suma una digitalización creciente y omniabarcante) Estos se han convertido en los principales detentores de estas verdades, configurando así una imagen del mundo que se impone como una totalidad sin fisuras, sin afuera y de la que parece imposible escapar. Es tal la vehemencia, recurrencia, verosimilitud y carácter homogeneizante de los mismos que la posibilidad de una toma de distancia crítica es cada vez más improbable y requiere, a su vez, mayor esfuerzo.

Con los medios se cumple, paradigmáticamente, la descripción platónica de la ignorancia como creer que se sabe (en la medida en que ponen a disposición casi de la totalidad) los discursos presuntamente verdaderos a partir de los cuales es posible opinar sobre todos los temas que están bajo su dominio. Cualquiera puede saber de política, medicina, historia, mecánica, avances científicos y un sin número de cuestiones, sin habérselas, ni de lejos, apropiado.

No se trata, sin embargo, de un plan maquiavélico de los medios en relación con el cual audiencias (o clientes, como las hemos denominado) son víctimas inermes. Por el contrario, en el engaño general que muchas veces los medios promueven, los auditorios juegan un papel cada vez más activo. Es decir, en la relación comprensión-pseudocomprensión (que acontece en el escenario de las industrias culturales, entre las que se cuenta la industria de la información) se multiplican a diario equívocos promovidos tanto por los medios como por sus destinatarios. Estos últimos, por otra parte, tienen un papel cada vez más protagónico y, por lo mismo, constituyen potencialmente la posibilidad que aún les queda a los destinatarios, de asumir una posición crítica y una comprensión más genuina de los fenómenos sociales.

\section{La industria cultural}

Se podría caracterizar a la época actual como una época dominada por un ambiente de escepticismo intelectual, agravado por la apariencia de comprensión que construye la hegemonía de los medios masivos. 
"La idea que el mundo quiere ser engañado se ha hecho más real de lo que jamás pretendió ser. Los hombres no solo se dejan engañar con tal de que eso les produzca una satisfacción por fugaz que sea sino que incluso desean esta impostura [...] Presienten que sus vidas se hacen intolerables tan pronto como dejan de aferrarse a satisfacciones que, para decirlo latamente, no son tales" (Adorno, 2008: 299).

Esta premisa es consecuente con el concepto de "industria cultural"1 con el que los autores pretendieron dirigir la atención y los esfuerzos reflexivos hacia los efectos de la vinculación moderna entre las formas culturales y las mercancías o, en otros términos, hacia el devenir de "mercancía" de los bienes culturales. Este concepto nombraba también la incidencia de los medios masivos sobre lo social, así como sobre los individuos particulares. El trasfondo de dicha reflexión fue la sospecha de que el dominio de la utilidad podría traer como consecuencia la alineación, el devenir de "mercancía" de la información y una creciente (y aparentemente sin contrapartida) uniformización del pensamiento, a la que se sumarían los efectos de la "amnesia" instantánea.

El concepto de "industria cultural" surgió como un concepto crítico con el que se pretendía vigilar, en el plano de estos fenómenos totalizantes y homogeneizantes, los abusos del poder. Pese a la generalización de cierta comprensión opuesta, este concepto no procedió según el criterio de "todo tiempo pasado fue mejor", ni pretendió una anacrónica e ingenua vuelta al pasado. La crítica a los medios no se les dirige a estos en tanto medios, sino más bien al espíritu que les sirve de suelo y que hace pasar todo lo humano, también la comunicación y la información, por el rasero de la utilidad económica.

La crítica se dirige a la teleología inmanente de las sociedades de producción, para la cual el fin es siempre la ganancia, en aras de la cual todo medio, incluso el bárbaro, está justificado de antemano. Se dirige al principio de la comercialización de la información en detrimento del contenido y a la consiguiente trivialización de los "productos autónomos del espíritu"2. La reflexión en torno a los medios masivos era también del orden de la esperanza, expresada por Bourdieu:

"Tengo la esperanza de poder contribuir a dotar de medios o de armas a todos aquellos que, dentro de las profesiones relacionadas con la imagen, luchan por evitar que, lo que hubiera podido convertirse en un extraordinario instrumento de democracia directa, no acabe por serlo de la opresión simbólica" (Bourdieu, 1997: 31).

1 Es necesario distinguir entre "industria cultural" y "cultura de masas", que fue el concepto utilizado en primera instancia y al que Adorno y Horkheimmer decidieron renunciar, para eludir la tentación de "abogados y comerciantes" de la cultura a entenderlo como la cultura que brota democráticamente, algo así como la "verdad del pueblo".

2 El concepto de autonomía es elaborado por Adorno y Horkheimmer con miras a delimitar la especificidad, respecto de las mercancías, de los productos del espíritu. La autonomía es toma de distancia crítica y oposición frente a la opinión y es condición ineludible de todo pensamiento auténtico. 
Se hace esta aclaración porque el concepto de "industria cultural" tiende a entenderse de dos modos: a) como el resultado de una nostalgia anacrónica y romántica o b) como denuncia de fenómenos que deben ser pensados y tenidos en cuenta, más no de modo perentorio. Estas dos modalidades de comprensión sitúan el concepto como producto de un debate intelectual entre la posibilidad de una reconciliación y la reserva en relación con los medios masivos.

La reconciliación asume el argumento de la democratización de la cultura y la reserva del riesgo de la alienación. En relación con el primero de los argumentos, es posible verificar (al menos en nuestro medio) que los destinatarios directos de tal efecto democrático no hacen más que reproducir actitudes preformadas por los medios mismos (léase polarización, en el mejor de los casos), con lo que el segundo de los argumentos (el de la reserva) termina por hacerse perentorio. Más aún si se tienen en cuenta los evidentes efectos que dicha reproducción acrítica tiene sobre lo real.

Quizá sea entonces la hora de oponerse, a partir de dichos efectos, a la hipótesis del carácter inofensivo (quizás por democrático ${ }^{3}$ ), de la industria cultural. Esta comporta riesgos cuya genealogía derivaban Adorno y Horkheimmer de su obediencia a la demanda. Una obediencia que, como lo condensa Nietzsche (1996: 169), "termina por corromper, no solo el pensamiento sino, a la larga, también el espíritu". El espíritu se corrompe en virtud del beneficio de una información que "in-forma" pobremente a sus públicos prefabricando (en series cada vez más maniqueas, ingenuas y superfluas) sus discusiones y pareceres. Una dialéctica se instala entre la "industria cultural" y sus clientes: la demanda es demanda de homogenización, de normalidad y a su vez dicha demanda se constituye en un "a priori social".

La avidez de novedades es prefabricada por las novedades mismas y sus informadores (cuya escucha y lectura reiterativa e irrestricta) termina por oscurecer cualquier posibilidad de comprensión. En una época como la actual, en la que los avances tecnológicos relativos a la comunicación han alcanzado la cota superior, no estamos (y esto se ha convertido en un lugar común) propiamente mejor informados. Sin embargo, no por haberse convertido en un lugar común, lo cual quizá constituya una suerte de neutralización, deja de ser verdad lo que ya Heidegger (1995: 167) advertía: "No por mucho hablar acerca de algo se garantiza en lo más mínimo el progreso de la comprensión. Al contrario: el prolongado discurrir sobre una cosa la encubre y proyecta sobre lo comprendido una aparente claridad, es decir, la incomprensión de la claridad".

Esta incomprensión alcanza en nuestro contexto un carácter autoritario en el que la opinión se ha convertido en dogmático fanatismo a partir de un decir y volver a decir que, aún cuando no tuviera la intención de crear una pseudorealidad, termina por crearla en virtud

3 El concepto de democracia, como muchos otros, ha terminado por hacer parecer inofensivo todo aquello con lo que tenga vecindad. Valdría la pena evaluar a qué complicidades, más que vecindades, ha servido el presunto carácter inofensivo de éste y otros conceptos. 
del contrato de veracidad de los medios. La obstrucción de la discusión, de la curiosidad, del disenso, constituye, de suyo, una imposibilidad real de pensamiento y de acción política. El don de la ubicuidad que los medios simulan, la preformación de lo que debe o no ser importante, desarraigan al individuo del mundo en el que vive y de la necesaria posición crítica.

Volviendo a la posibilidad expresada en un comienzo a partir de la cita de Heidegger: así como el espíritu se ha convertido en expresión de la ceguera social, también tiene la posibilidad de verificar la incompatibilidad con la ideología dominante, la posibilidad de una toma de distancia crítica respecto de esta misma ceguera, que consiste en no ser capaz de pensar nada que no pueda referirse al criterio de la utilidad. La posibilidad que le queda a la pseudocomprensión (en términos de Heidegger), a la preformación (en términos de Adorno) es la de aventurar un lenguaje que pueda florecer al margen de los discursos operacionales, haciendo resistencia al bloque utilitarista de la legitimidad al que responde todo gremio económico o político.

Dicha posibilidad reside, al decir de Benjamín, en poner un poco en suspenso el imperativo de transformar (con miras a la explotación) el mundo y atreverse a interpretarlo, en darle un lugar al desciframiento de los fenómenos sociales a despecho de los intereses más poderosos de lo social tales como el rating, la medición de la audiencia y el indicador que se ha apoderado de la mentalidad, tanto mediática como educativa e incluso relativa a las políticas de salud.

La crítica a la tendencia homogeneizante de los medios no es, entonces, una crítica a los periodistas (que la verdad no la pasan muy bien cuando son autónomos) sino un esfuerzo por intentar vincular su hacer a la reflexión que podría oponerle un poco de resistencia al dominio de la instrumentalización del pensamiento. Estos, además de ser manipuladores, son esencialmente manipulados por las exigencias de productividad y de conservación del orden simbólico sin fisuras ni oscuridades (Charadeau, 2003: 76).

Por lo mismo utilizan estrategias a partir de las cuales el disenso sea impensable: divertimento (ocupación del tiempo), carácter acomodaticio respecto de los gustos, superfluidad, interés general y anulación de la posibilidad crítica:

"Los sucesos tienen el efecto de crear un vacío político, de despolitizar o de reducir la vida del mundo a la anécdota o al cotilleo que puede ser nacional o planetario, con la vida de las estrellas o de las familias reales, al fijar y mantener la atención en unos acontecimientos carentes de consecuencias políticas, que se dramatizan para extraer la lección pertinente" (Bourdieu, 1997: 74).

Sumado a lo anterior, está el devenir espectáculo comercial de la realidad política, devenir que en nuestro contexto es particularmente sensible. Más grave quizá, que elevar lo anodino al ámbito de lo necesario, resulta que lo necesario se presente bajo la apariencia de lo irrelevante y hasta risible. 


\section{Lo que cabría esperar}

Si algo cabe esperar en el estado actual de cosas es una reivindicación del pensamiento, un resurgir del mismo a partir de las ruinas de lo superfluo, de lo (en términos de Adorno), "bárbaro". Para los individuos particulares, la opacidad de la realidad es directamente proporcional al tráfico, la violencia y la indiferencia social. El mal ha devenido, como ya lo afirmaba Baudrillard, "transparente" y la barbarie se cuenta entre los divertimentos de la actualidad.

Cabe esperar que lo que ha dado legitimidad y pertinencia al discurso filosófico, sociológico, hermenéutico y semiológico (a saber, la vocación de volverse contra el falso consenso) no sea arrasado final y fatalmente por la fuerza irresistible de lo superfluo en la que el pensamiento mismo pierda del todo su verdad y su vocación de verdad. Cabe esperar que la resignación no colonice las escasas playas de libertades elementales en las que reside la última, mínima esperanza, de la redención. En este sentido, las instituciones universitarias y la educación humanística, que todavía tiene allí algún lugar, constituyen un espacio de esperanza.

$\mathrm{Al}$ interior de las instituciones que administran el pensamiento, puede erigirse algo que (aún siendo mínimo) no sea tan solo cultura administrada y pensamiento acrítico. Para ello hace falta que en las aulas deje de favorecerse la imparcialidad imperturbable y la especulación vaga y se creen espacios de verdadera formación académica: de fidelidad al pensamiento crítico y de una bien comprendida compasión por las víctimas.

Lo anterior podría resumirse en una decidida reivindicación de la razón práctica a partir de la cual se rehabilite el espacio de cuestionamiento, formulación y fundamentación de juicios de valor. Surge aquí el escepticismo, que se convierte en la mayoría de los casos en una excusa de los maestros y que Adorno y Horkheimmer formulaban así:

"Es difícil aplicar el concepto de responsabilidad a la juventud estudiantil de hoy, en el mismo sentido que a otras anteriores. Sin embargo no siento duda alguna de que, pese a todo, hay algo decisivo que ha permanecido idéntico: también ahora la responsabilidad del estudiante reside en que no se acomode a los poderes desespiritualizadores, sino que los reconozca y distinga" (Adorno y Horkheimer, 2009: 82).

La civilización marcha a contracorriente de lo humano. No es posible esperar que de la progresista y optimista fe en la tecnología (y sus nunca bien ponderados avances) pueda derivarse, al margen de la crítica, alguna suerte de modificación: "lo que tiene la culpa de las desgracias no es la racionalización del mundo, sino la irracionalidad de esta racionalización" (Adorno y Horkheimer, 2009: 92).

La crítica, y la justificación de esta actitud vital del pensamiento (justificación que hace posible la crítica misma) deben ser objetivos fundamentales de todo proyecto académico. Esta fundamentación, sin embargo, es cada vez más difícil en virtud de la, ya vieja y cada 
vez más acentuada deslegitimación de la tradición reflexiva, en virtud de la cual ha perdido, casi totalmente, su vigencia. Lo anterior está agravado por el hecho de que la guerra haya encontrado, con mucha frecuencia, una justificación en la racionalidad. Lo que se instala en el lugar de la utopía, sigue siendo el único esfuerzo legítimo, la única batalla que (con justicia) valdría la pena sostener, a fin de continuar siendo mínimamente humanos.

\section{Fuentes consultadas}

\section{Adorno, $T$.}

_(2009). Dialéctica de la ilustración. Madrid: Trotta.

_(2008). Crítica cultural y sociedad I. Prismas sin imagen directriz. Madrid: Akal.

Adorno, T. y Horkheimer, M. (2009). La industria cultural. Iluminismo como mistificación de masas. Buenos Aires: Suramericana.

Benjamin, W. (1989). Discursos interrumpidos. Volumen I. Buenos Aires: Taurus.

Bourdieu, P. (1997). La televisión. Barcelona: Anagrama.

Charaudeau, P. (2003). El discurso de la información. La construcción del espejo social. Barcelona: Gedisa.

Heidegger, M. (1995). El ser y el tiempo. Buenos Aires: Fondo de Cultura Económica.

Horkheimmer, M. y Adorno T. (1992). Sociológica. Madrid: Taurus.

\section{Nietzsche, $\mathbf{F}$.}

_(1995). Así habló Zaratustra. Madrid: Alianza.

_(1994). La genealogía de la moral. Madrid: Alianza.

Platón. (1988). Diálogos. Madrid: Gredos. 